\title{
A Spatial Analysis of Negative Health Outcomes for Newborns Among Undocumented Immigrant Populations in the United States
}

Brittnee Boyer ( $\sim$ brittneewestra98@gmail.com )

Brigham Young University

Jenna Shaw

Brigham Young University

Ida Tovar

Brigham Young University

Rebekah Read

Brigham Young University

Chantel Sloan

Brigham Young University

\section{Research Article}

Keywords: Negative birth outcomes, undocumented immigrants, spatial analysis

Posted Date: February 19th, 2021

DOI: https://doi.org/10.21203/rs.3.rs-215321/v1

License: (c) (1) This work is licensed under a Creative Commons Attribution 4.0 International License. Read Full License 


\section{A Spatial Analysis of Negative Health Outcomes for Newborns Among Undocumented Immigrant Populations in the United States}

Brittnee Boyer ${ }^{1}$, Jenna Shaw ${ }^{1}$, Ida Tovar ${ }^{1}, \operatorname{Rebekah~Read~}^{1}$, Chantel Sloan ${ }^{1}$

${ }^{1}$ Department of Public Health, Brigham Young University, Provo, Utah, USA

Correspondence to brittneewestra98@gmail.com 


\begin{abstract}
Background

Undocumented immigrants constitute a highly vulnerable population that may experience increased risk of negative health outcomes for newborn children. The spatial relationship between the proportion of undocumented immigrants residing in an area and negative birth outcomes has not been studied on a national scale, although real and perceived access to healthcare are unlikely to be geographically consistent.
\end{abstract}

\title{
Methods
}

We compiled estimates of the percent of undocumented immigrants, negative newborn health outcomes, and socioeconomic data for 173 counties in the United States, drawn and calculated from publicly-available databases. We used a negative binomial regression model to determine the relationship between undocumented immigrants and three negative birth outcomes: NICU admission, low birth weight, and infant mortality. Incidence rate ratios are reported as the primary analytical metric.

\section{Results}

A higher proportion of undocumented immigrants in a county was not a significant predictor of higher rates of negative health outcomes for newborns. However, counties with a higher Hispanic/Latino population, higher African American population, and higher percentages of persons with bachelor's degrees were all associated with poorer outcomes. NICU admission rates were higher in counties with a high Hispanic/Latino population (IRR: 1.31) and counties with a high African American population (IRR: 1.29). Low birth weight had a similar trend (High Hispanic/Latino population IRR: 1.39; High African American population IRR: 1.32), along with infant mortality (High Hispanic/Latino population IRR: 1.37; High African American population IRR: 1.30). Those with high proportions of Republican voters were less likely to have negative birth outcomes; the incidence rate ratio for negative birth outcomes among a high level of Republican voters was 0.74 for admission into the NICU and 0.72 for low birth weight.

\section{Conclusion}

We did not find a statistical association between counties with high rates of undocumented immigrants and negative health outcomes for newborns. This could be the result of the healthy immigrant effect, incomplete data on undocumented immigrants, or there may be an association not statistically detectable at such a large spatial scale.

\section{Keywords}

Negative birth outcomes, undocumented immigrants, spatial analysis 


\section{Background}

As of 2018, more than 44.7 million immigrants lived in the United States (1). According to the American Community Survey (ACS), one in seven U.S. residents is foreign born (1). About 25\% of all immigrants originated from Mexico with the majority of the remaining percentage coming from China, the Philippines, India, and El Salvador (2).

Healthcare for undocumented immigrants varies greatly on state and county levels due to differing economic situations, political climates and healthcare policies. Currently, undocumented immigrants are unable to apply for private health insurance and federal policy bars them from accessing Medicare and Medicaid. However, there are select health centers funded by the federal government required to provide medical services to anyone in need, including undocumented immigrants (3). States such as Texas passed legislation allowing undocumented immigrant women access to perinatal care through the Children's Health Insurance Program (CHIP). One study done on the effectiveness of CHIP reported that as healthcare resources are expanded to undocumented mothers, negative birth outcomes decrease (4).

Immigrant mothers going through the U.S. healthcare system often face barriers such as discrimination due to differences in culture, language, nationality, race and gender $(9,10)$. Maternal care barriers are often a result of low cultural competency within the healthcare system, which has been shown to leave immigrant women vulnerable to chronic stressors such as social isolation, breaches or denied access to healthcare coverage during pregnancy $(9,10,11)$. Pregnant immigrants are often not familiar with the healthcare system, leaving resources underutilized within this population $(9,12)$. A recent study showed that if pregnancy related complications occurred, immigrant mothers were less likely to receive needed care after the event (13). Research also suggests healthcare providers' limited knowledge healthcare providers about undocumented migrant rights to healthcare is a critical barrier to overcome in order to improve birth outcomes (8).

While a majority of research suggests maternal based vulnerability among Latin immigrants, a portion of studies suggest the children of immigrants have less risk factors related to low birthweight than their mother (14). In research literature this epidemiological paradox is often called the healthy-immigrant effect or "healthy migrant effect" $(15,16,17)$. Some researchers believe this occurs because current population surveys such as the American Community Survey, do not include questions about immigrants' legal status which may lead to an overgeneralization (18). This may also be a true phenomenon due to immigration choices based on health status. Mothers who acknowledge their risk factors may decide to forgo migration in comparison to expectant mothers who feel they can make the journey safely (17).

Political divisions surrounding undocumented immigrant communities in the United States have risen over recent years. According to data collected by the Pew research center in 2017, Democrats were twice as likely as Republicans to say "Immigrants strengthen the country" whereas in 2002 there was almost no difference in response between parties (6). Migrants during the first half of the twentieth century were ineligible for welfare through many formal and 
informal policies and practices on a state and local level (7). Policy evaluation reveals immigrants continue to face confusion about rules and regulations surrounding health resources, risk of deportation or interference with their ability to become a citizen $(7,8)$. In this study, we sought to determine if the complicated situation undocumented immigrant mothers face results in geographic patterns of negative birth outcomes that could indicate a need for increased resources and policy adjustments in those locations.

\section{Methods}

\section{Data Sources}

Most of the public databases we used included data for every county in the nation. However, estimates of undocumented populations were not universally available and limited the number of counties we could analyze. We accessed undocumented immigrant population data through the Data Hub of the Migration Policy Institute (MPI). The MPI developed a method for estimating legal status based on populations in the U.S. Census Bureau's 2012-16 American Community Survey. Their estimates were available for 173 US counties.

Demographic data were extracted from the United States Census Bureau American Community Survey (ACS). County-level demographic profiles were 1-year summaries from 2016, assuring that all data came from the same year. Data included percentages of the population identifying as African American, Hispanic/Latino, living at or below poverty, and those 35 years and older who have a bachelor's degree. We merged the MPI data with the ACS data using SAS software (v.9.4).

Data on birth outcomes and prenatal care were extracted from CDC Wonder. Data from CDC Wonder consisted of reports on NICU admission, low birthweight ( $<2500$ grams), late or no prenatal care, and infant mortality in 2016 (19). Late or no prenatal care was calculated by counting pregnant mothers who received prenatal care only in the third trimester or no prenatal care at all. Infant mortality included any death of an infant before the age of 1 . Birth count data were also obtained from CDC Wonder.

Data on political leaning was taken from the MIT Election Data and Science Lab. They assign county-level political leanings by obtaining the percentage of votes for each political party. Data were primarily based on votes cast in the 2016 presidential election.

Each variable was split into three groups-low, medium, and high rates of each parameter to calculate the incidence rate ratios. The size of each group was determined by using tertiles. The lowest level was used as the reference group within the regression.

\section{Data Analysis}

Conventional linear regression analyses assume that the dependent variable is continuous with a constant variance. Our data included frequencies of binomial response variables such as whether or not a newborn baby was admitted into the NICU. The data was expected to be overdispersed, and the negative binomial regression results showed the dispersion parameter to be positive. This proved that the explanatory variables were overdispersed for all response variables, justifying the 
use of the negative binomial distribution. The negative binomial distribution is a generalization of the Poisson distribution, which is typically used for modeling count data. The negative binomial models are an adjustment to Poisson, in that they add an extra parameter to account for overdispersion.

The following model was used as the foundation for data analysis:

$\log (\mathrm{Yi})=\operatorname{Intercept}+\beta 1 \mathrm{X} 1 \mathrm{i}+\beta 2 \mathrm{X} 2 \mathrm{i}+\beta 3 \mathrm{X} 3 \mathrm{i}+\mathrm{i}$

Where $\mathrm{Yi}=$ the response variable, which is the number of negative birth outcomes per county i. $\beta$ $=$ the coefficient per variable, which is to say, how much $Y$ will increase per every 1 unit increase of X. Variables (X) were undocumented immigrant population, political leaning, race, education, percent below poverty per county, and percent of pregnancies with late or no prenatal care. $=$ the error term. The response variables are placement in NICU after birth, low birthweight, and infant mortality.

In addition to the negative binomial regression, the incidence rate ratio (IRR) was analyzed and interpreted for all explanatory variables.

\section{Results}

The analysis included birth outcome, immigration status, socioeconomics and political leanings from 173 counties in the United States. After cleaning and merging data into one dataset, the distributions of most variables were normally distributed with the exception of the African American and Hispanic/Latino population distributions, which were both skewed right [see Figure 1, appendix]. Pearson's correlations between every pair of variables were calculated [see Table 3, appendix], and percent voted Democrat and percent voted Republican were highly correlated $(\mathrm{r} 2=-0.972)$. The percent voted Republican was selected as an explanatory variable of interest, and the percent voted Democrat was removed from analysis [see Figure 2, appendix].

Table 1 includes the mean percent of each variable within each level, along with a standard deviation and p-value. All results were statistically significant except the percent African American and percent of births with late or no prenatal care. The highest mean percentage of Hispanic/Latino people per county was found in the high level of percent undocumented (mean $=39 \%$ ), as with percent in poverty (mean $=15 \%$ ).

The percent of the overall population that was undocumented was not significant in predicting a negative birth outcome in our study counties [see Table 2]. However, having a high Hispanic/Latino population was consistently more likely to have negative birth outcomes than counties with a low Hispanic/Latino population for NICU admission (IRR: 1.31, C.I.: 1.04-1.65, p-value: 0.02), low birth weight (IRR: 1.39, C.I.: 1.10-1.75, p-value: 0.01), and for infant mortality (IRR: 1.37, C.I.: 1.09-1.72, p-value: 0.01). The African American population followed a similar pattern for all negative birth outcomes: NICU admission (IRR: 1.29, C.I.: 1.07-1.56, pvalue: 0.01 ), low birth weight (IRR: 1.32 , C.I.: $1.09-1.60$, p-value $<0.01$ ), and infant mortality (IRR: 1.30, C.I.: 1.08-1.57, p-value: 0.01). 
Counties with a high Republican-voter population were less likely to have negative birth outcomes for all variables except infant mortality. The incidence rate ratio for negative birth outcomes among a high level of Republican voters was 0.74 (C.I.: 0.0.62-0.88, p-value $<0.01$ ) for admission into the NICU and 0.72 (C.I.: 0.60-0.85, p-value $<0.01$ ) for low birth weight. Counties with medium rates of bachelor's degrees were consistently more likely to have negative birth outcomes for all response variables than counties with low rates of bachelor's degrees.

The negative binomial regression analysis produced few statistically significant results [see Table 4, appendix].

Table 1

Stratification of the undocumented population by low, medium, and high levels in each county.

\begin{tabular}{|l|l|l|l|l|l|l|l|}
\hline & \multicolumn{3}{|l|}{ Proportion of Population that is Undocumented } & \\
\hline & \multicolumn{2}{|l|}{$\begin{array}{l}\text { Low }(0.00- \\
0.032)\end{array}$} & \multicolumn{2}{l}{$\begin{array}{l}\text { Medium }(0.033- \\
0.059)\end{array}$} & \multicolumn{2}{l}{$\begin{array}{l}\text { High }(0.060- \\
0.126)\end{array}$} & \\
\hline & Mean & $\begin{array}{l}\text { Std } \\
\text { Dev }\end{array}$ & Mean & Std Dev & Mean & $\begin{array}{l}\text { Std } \\
\text { Dev }\end{array}$ & $\begin{array}{l}\text { P- } \\
\text { value }\end{array}$ \\
\hline Proportion of Births in NICU & 0.10 & 0.03 & 0.10 & 0.02 & 0.08 & 0.03 & $\begin{array}{l}0.01 \\
* *\end{array}$ \\
\hline $\begin{array}{l}\text { Proportion of Births with Low } \\
\text { Birth weight }\end{array}$ & 0.08 & 0.01 & 0.08 & 0.01 & 0.07 & 0.01 & $\begin{array}{l}<0.01 \\
* *\end{array}$ \\
\hline Infant Mortality & 0.01 & $<0.01$ & 0.01 & $<0.01$ & $<0.01$ & $<0.01$ & $\begin{array}{l}<0.01 \\
* *\end{array}$ \\
\hline Proportion in Poverty & 0.12 & 0.04 & 0.13 & 0.05 & 0.15 & 0.06 & $\begin{array}{l}0.01 \\
* *\end{array}$ \\
\hline Proportion African American & 0.17 & 0.11 & 0.14 & 0.11 & 0.13 & 0.15 & 0.33 \\
\hline Proportion Hispanic/Latino & 0.12 & 0.10 & 0.21 & 0.12 & 0.39 & 0.21 & $\begin{array}{l}<0.01 \\
* *\end{array}$ \\
\hline Proportion Republican & 0.43 & 0.11 & 0.42 & 0.14 & 0.33 & 0.14 & $\begin{array}{l}<0.01 \\
* *\end{array}$ \\
\hline $\begin{array}{l}\text { Proportion with Bachelor's } \\
\text { Degree }\end{array}$ & 0.22 & 0.04 & 0.23 & 0.06 & 0.19 & 0.07 & $\begin{array}{l}<0.01 \\
* *\end{array}$ \\
\hline $\begin{array}{l}\text { Proportion of Births with } \\
\text { Late/No Prenatal Care }\end{array}$ & 0.06 & 0.03 & 0.06 & 0.03 & 0.06 & 0.03 & $\begin{array}{l}0.49 \\
* *\end{array}$ \\
\hline
\end{tabular}

**Value is statistically significant. Significance of $\mathrm{p}$-value was determined by $<0.05$. 
Table 2

Incidence Rate Ratios for all explanatory variables with response variables. Ratios are in reference to the low level of each explanatory variable.

\begin{tabular}{|c|c|c|c|c|c|c|c|c|c|}
\hline & \multicolumn{3}{|c|}{ NICU } & \multicolumn{3}{|c|}{ Low BW } & \multicolumn{3}{|c|}{ Infant Mortality } \\
\hline & IRR & C.I. & $\mathrm{P}$ & IRR & C.I. & $\mathrm{P}$ & IRR & C.I. & $\mathrm{P}$ \\
\hline Med Undoc & 1.16 & $0.98-1.38$ & 0.08 & 1.12 & $0.94-1.32$ & 0.20 & 1.12 & $0.95-1.32$ & 0.18 \\
\hline High Undoc & 0.86 & $0.68-1.07$ & 0.18 & 0.88 & $0.70-1.10$ & 0.26 & 0.88 & $0.71-1.10$ & 0.27 \\
\hline Med Pov & 1.07 & $0.91-1.26$ & 0.41 & 1.07 & $0.91-1.26$ & 0.38 & 1.00 & $0.86-1.26$ & 0.98 \\
\hline High Pov & 1.16 & $0.96-1.39$ & 0.13 & 1.12 & $0.93-1.35$ & 0.22 & 1.31 & $1.09-1.57$ & $\begin{array}{l}<0.01 \\
* *\end{array}$ \\
\hline Med AfAm & 1.05 & $0.89-1.23$ & 0.59 & 1.02 & $0.86-1.20$ & 0.84 & 0.95 & $0.81-1.12$ & 0.54 \\
\hline High AfAm & 1.29 & $1.07-1.56$ & $\begin{array}{l}0.01 \\
* *\end{array}$ & 1.32 & $1.09-1.60$ & $\begin{array}{l}<0.01 \\
* *\end{array}$ & 1.30 & $1.08-1.57$ & $\begin{array}{l}0.01 \\
* *\end{array}$ \\
\hline Med Hispanic & 0.94 & $0.80-1.12$ & 0.51 & 0.88 & $0.74-1.04$ & 0.14 & 0.85 & $0.72-1.01$ & 0.06 \\
\hline High Hispanic & 1.31 & $1.04-1.65$ & $\begin{array}{l}0.02 \\
* *\end{array}$ & 1.39 & $1.10-1.75$ & $\begin{array}{l}0.01 \\
* *\end{array}$ & 1.37 & $1.09-1.72$ & $\begin{array}{l}0.01 \\
* *\end{array}$ \\
\hline Med Repub & 1.14 & $0.98-1.33$ & 0.09 & 1.11 & $0.95-1.29$ & 0.20 & 1.02 & $0.88-1.18$ & 0.83 \\
\hline High Repub & 0.74 & $0.62-0.88$ & $<0.01 * *$ & 0.72 & $0.60-0.85$ & $\begin{array}{l}<0.01 \\
* *\end{array}$ & 0.85 & $0.71-1.01$ & 0.06 \\
\hline Med Bach & 1.30 & $1.10-1.53$ & $<0.01 * *$ & 1.23 & $1.04-1.45$ & $\begin{array}{l}0.01 \\
* *\end{array}$ & 1.23 & $1.05-1.44$ & $\begin{array}{l}0.01 \\
* *\end{array}$ \\
\hline High Bach & 0.94 & $0.77-1.14$ & 0.53 & 1.02 & $0.83-1.24$ & 0.88 & 0.93 & $0.77-1.13$ & 0.47 \\
\hline Med Prenatal & 0.81 & $0.61-1.08$ & 0.15 & 0.86 & $0.64-1.15$ & 0.30 & 0.98 & $0.73-1.31$ & 0.89 \\
\hline High Prenatal & 0.67 & $0.49-0.91$ & $\begin{array}{l}0.01 \\
* *\end{array}$ & 0.78 & $0.57-1.06$ & 0.12 & 0.84 & $0.62-1.16$ & 0.29 \\
\hline
\end{tabular}

$* *$ Value is statistically significant. Significance of $\mathrm{p}$-value was determined by $<0.05$. 
Maps

Percent of Births in NICU

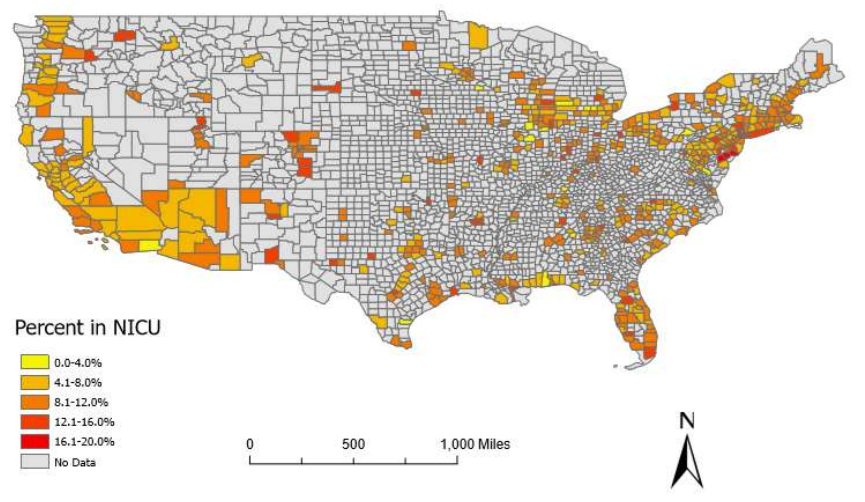

U.S. Infant Mortality

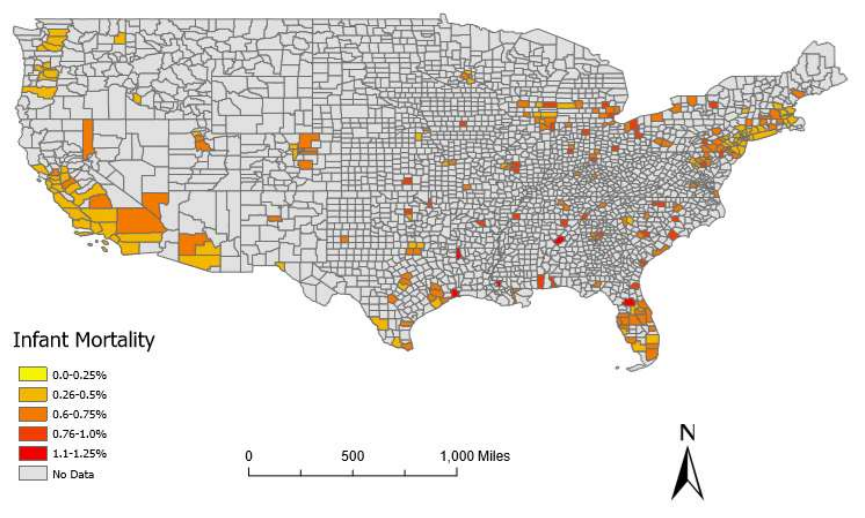

Percent of Births with Late or No Prenatal Care

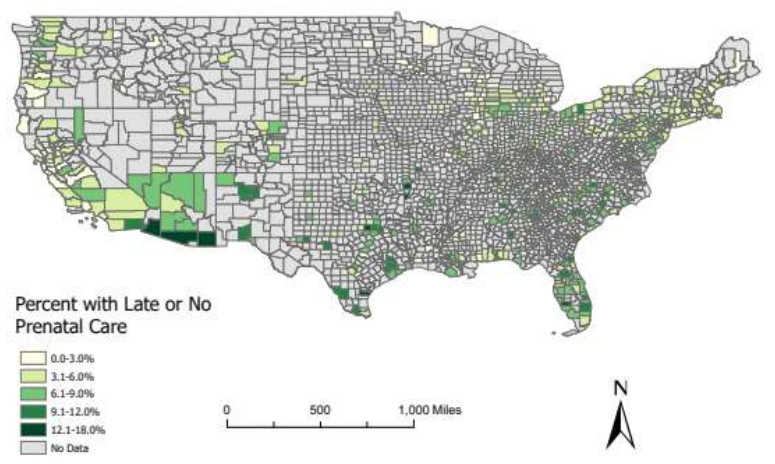

Percent of Births with Low Birthweight

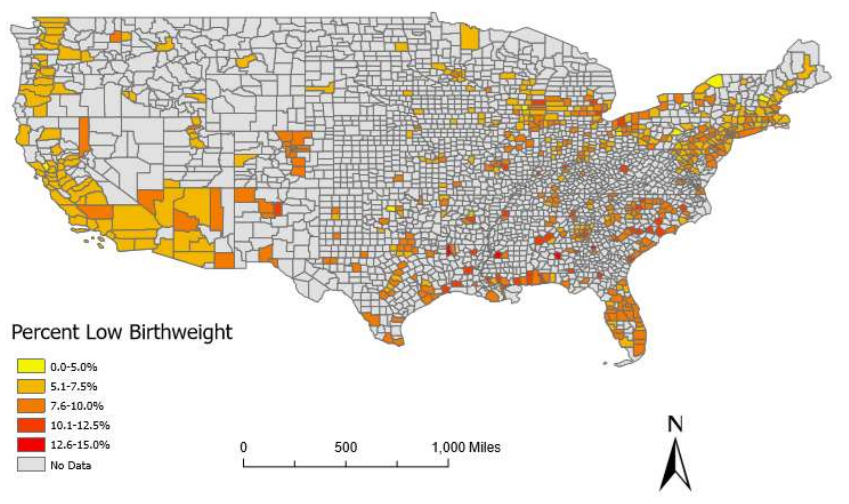

Unauthorized Immigrants in the U.S.

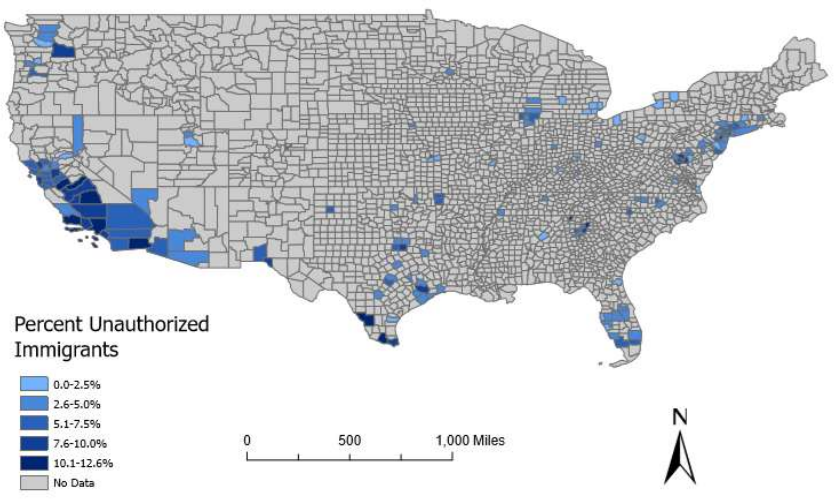

Percent of Population in Poverty

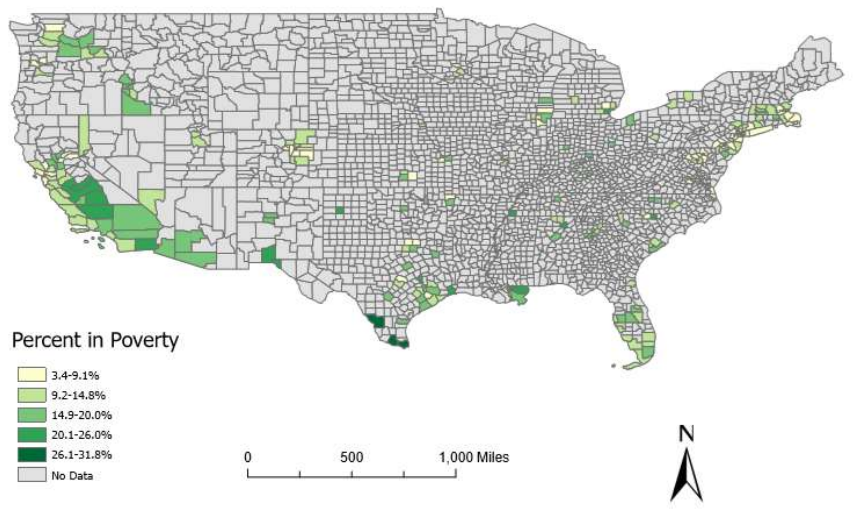


Hispanic/Latino Population in the U.S.

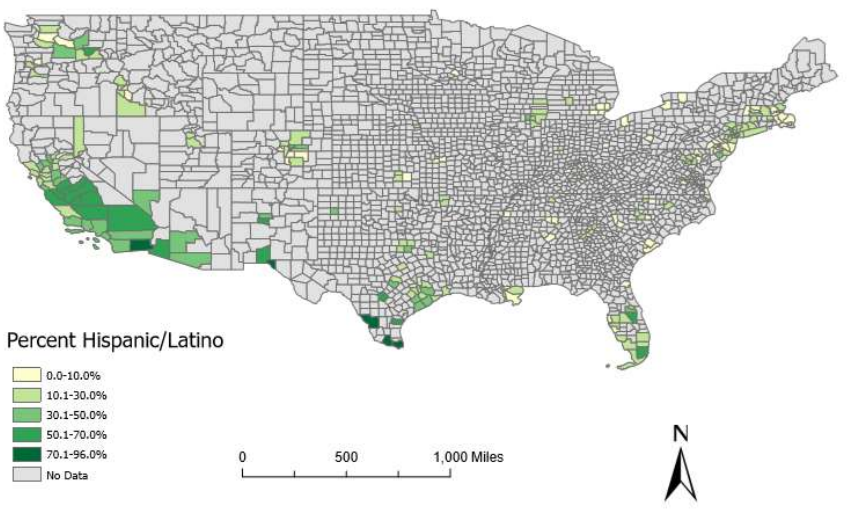

Percent Voted Republican 2016

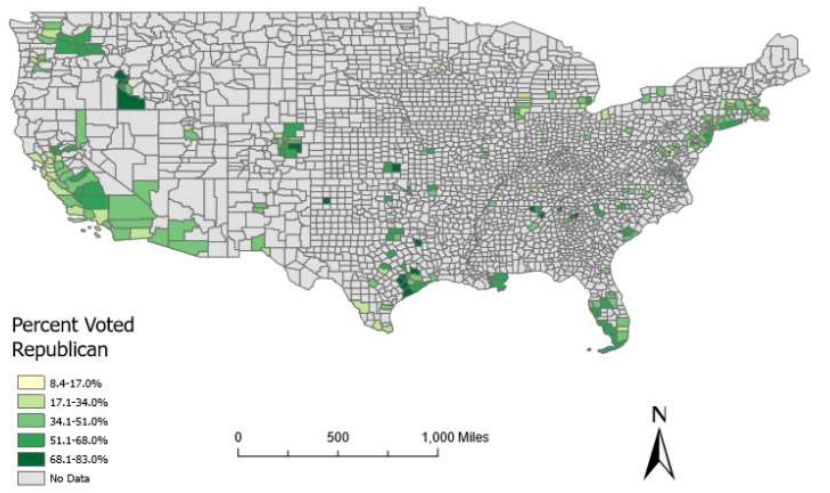

African American Population in the U.S.

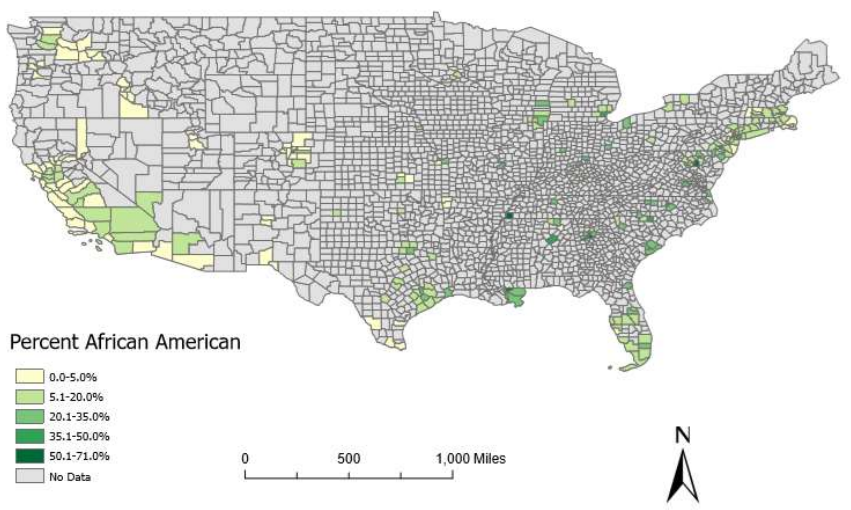

Percent of U.S. Population with Bachelor's Degree

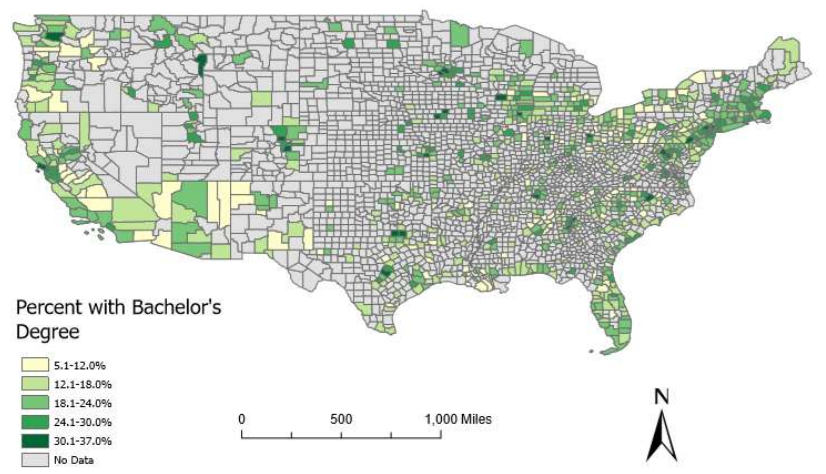

\section{Discussion}

This was the first study to spatially analyze the relationship between the United States undocumented population and various negative birth outcomes. The results showed that a higher percentage of undocumented immigrants was not a significant predictor of higher rates of negative birth outcomes. Other explanatory variables, however, produced significant results in relation to negative birth outcomes, such as the Hispanic/Latino population and the Republican voters population.

The relationship between the undocumented population and negative birth outcomes was, to some extent, surprising. The alternate hypothesis that higher rates of undocumented immigrants resulted in higher rates of negative birth outcomes was based on the idea that immigrants are more likely to be low-income. This hypothesis was also based upon the understanding that undocumented immigrants frequently do not have access to healthcare, seeing that only a small proportion of undocumented immigrants enroll in Medicaid due to fear of deportation (14). However, despite these factors, results showed that undocumented immigrants could have similar or even better birth outcomes as U.S. citizens. Several studies align with the results of 
this study. One study found that the undocumented population in Colorado was less likely to deliver low birthweight babies in comparison to the rest of the population (14). Another study similarly found that people born in the U.S. are more likely to deliver low birthweight babies than foreign born people (16). This study adds to previous research by concluding similar results in relation to undocumented immigrants and low rates of low birth weights. These lower rates proved true for other variables as well, like NICU admission, late or no prenatal care, and infant mortality.

A large portion of the undocumented immigrants in the United States are Hispanic/Latino. In 2016, over 50\% of U.S. immigrants came from Latin American countries (20). The spatial distributions of percent undocumented and percent Hispanic/Latino are moderately correlated (r2 $=0.69, \mathrm{p}$-value $<0.0001)$ [see figure 2]. However, the analysis of the Hispanic/Latino population did not follow the same pattern as the undocumented population in regards to negative birth outcomes. For all response variables, counties with a high Hispanic/Latino population were consistently more likely to have negative birth outcomes than a low Hispanic/Latino population. For example, counties with a high Hispanic/Latino population were 42.38 times more likely to have late or no prenatal care than counties with a low Hispanic/Latino population. Although a large proportion of undocumented immigrants are Hispanic/Latino, the results here likely represent those that are documented, or the children or grandchildren of Hispanic immigrants. Reed et al. further support this concept by explaining that the children of immigrants become "Americanized," and their risk of delivering a low birthweight infant is increased (14). A study in Texas also showed that undocumented Hispanic women who used CHIP (Children's Health Insurance Program) to access prenatal care had better birth outcomes than documented Hispanic women who used Medicaid (7). This suggests that the healthy immigrant effect may be responsible for our results. Through selective migration, decreased adverse health behaviors, and increased social support, undocumented immigrants often have better birth outcomes than other Hispanic/Latino women or other U.S. citizens.

Other demographic variables, such percent of the population that is African American and those with a bachelor's degree, also produced significant results. Counties with a high African American population were more likely to have negative birth outcomes than counties with a low African American population for all response variables. Additionally, a county with a medium level of people with a bachelor's degree were more likely to have negative birth outcomes than a county that had a low level of people with bachelor's degrees. Interestingly, a county with high levels of voters registered as Republican in 2016 was less likely to have negative birth outcomes than a county with a low level of Republican voters for all response variables except late or no prenatal care. For example, counties with a high level of Republican voters were 28 times less likely to have low birthweights than counties with low levels of Republican voters. This correlation between political ideology and birth outcomes suggests that further research needs to be conducted on the relationship between these variables.

\section{Limitations}

A major limitation to this study was the lack of undocumented immigrant data for all counties in the United States. Broader access to data on undocumented populations may have revealed 
different patterns. Another limitation with any study involving an undocumented population is that the numbers for this population are merely estimates pulled from a variety of sources. The estimates provided by the Migration Policy Institute which we used are commonly accepted as valid. With 173 counties, our study was adequately powered to identify trends.

\section{Conclusion}

This study demonstrated that counties with higher rates of undocumented immigrants in the U.S. have equal or better birth outcomes than counties with low rates of undocumented immigrants. The undocumented distribution is spatially similar to the Hispanic/Latino distribution, the latter showing higher rates of negative birth outcomes with higher rates of Hispanic/Latinos. Further research is recommended to determine if this trend is real and robust over time, and a deeper understanding of their relationship with local healthcare policy. 


\author{
Abbreviations \\ ACS: American Community Survey \\ PRWORA: Personal Responsibility and Work Opportunity Reconciliation Act \\ CHIP: Children's Health Insurance Program \\ GIS: Geographic Information System \\ MPI: Migration Policy Institute \\ SAS: Statistical Analysis System \\ MIT: Massachusetts Institute of Technology \\ CDC: Center for Disease Control and prevention \\ NICU: Neonatal Intensive Care Unit \\ IRR: Incidence Rate Ratio \\ C.I.: Confidence Interval
}




\section{References}

1. Bolter, J. B., Jessica Bolter Jeanne Batalova, Brittany Blizzard, and Jessica. Frequently Requested Statistics on Immigrants and Immigration in the United States.

Migrationpolicy.Org. February 12, 2020.

https://www.migrationpolicy.org/article/frequently-requested-statistics-immigrants-andimmigration-united-states

2. Lopez, G., \& Bialik, K. Key findings about U.S. immigrants. Pew Research Center. June 17, 2019. https://www.pewresearch.org/fact-tank/2019/06/17/key-findings-about-u-simmigrants/

3. Hoffman, J. What Would Giving Health Care to Undocumented Immigrants Mean? The New York Times. July 3, 2019.

https://www.nytimes.com/2019/07/03/health/undocumented-immigrants-health-care.html

4. Dang, B. N., Van Dessel, L., Hanke, J., \& Hilliard, M. A. Birth Outcomes Among LowIncome Women-Documented and Undocumented. The Permanente Journal, 2011;15(2):39-43.

5. Barkensjö, M., Greenbrook, J. T. V., Rosenlundh, J., Ascher, H., \& Elden, H. The need for trust and safety inducing encounters: A qualitative exploration of women's experiences of seeking perinatal care when living as undocumented migrants in Sweden. BMC Pregnancy and Childbirth, 2018;18(1):217. https://doi.org/10.1186/s12884-018$\underline{1851-9}$

6. Pew Research Center. The Partisan Divide on Political Values Grows Even Wider. Pew Research Center - U.S. Politics \& Policy. October 5, 2017. https://www.peoplepress.org/2017/10/05/the-partisan-divide-on-political-values-grows-even-wider/

7. Reese, E., \& Ramirez, E. The New Ethnic Politics of Welfare: Struggles Over Legal Immigrants' Rights to Welfare in California. Journal of Poverty, 2002;6(3):29-62. https://doi.org/10.1300/J134v06n03 02

8. Zimmermann, W., \& Fix, M. E. Declining Immigrant Applications for Medi-Cal and Welfare Benefits in Los Angeles County. Urban Institute. June 4, 2016. https://www.urban.org/research/publication/declining-immigrant-applications-medi-caland-welfare-benefits-los-angeles-county

9. Choi, S. K. Y., Henry, A., Hilder, L., Gordon, A., Jorm, L., \& Chambers, G. M. Adverse perinatal outcomes in immigrants: A ten-year population-based observational study and assessment of growth charts. Paediatric and Perinatal Epidemiology, 2019;33(6):421432. https://doi.org/10.1111/ppe. 12583

10. Mao, L., Stacciarini, J.-M. R., Smith, R., \& Wiens, B. An individual-based rurality measure and its health application: A case study of Latino immigrants in North Florida, USA. Social Science \& Medicine, 2015;147:300-308.

11. Gea-Sánchez, M., Gastaldo, D., Molina-Luque, F., \& Otero-García, L. Access and utilisation of social and health services as a social determinant of health: The case of undocumented Latin American immigrant women working in Lleida (Catalonia, Spain). Health \& Social Care in the Community, 2017;25(2):424-434. https://doi.org/10.1111/hsc. 12322 
12. Chavez, L. R., Cornelius, W. A., \& Oliver, W. J. Utilization of Health Services by Mexican Immigrant Women in San Diego. Women \& Health, 1986;11(2):3-20. https://doi.org/10.1300/J013v11n02_02

13. Wyrick, J. M., Kalosza, B. A., Coritsidis, G. N., Tse, R., \& Agriantonis, G. Trauma care in a multiethnic population: Effects of being undocumented. Journal of Surgical Research, 2017;214:145-153. https://doi.org/10.1016/j.jss.2017.02.006

14. Reed, M. M., Westfall, J. M., Bublitz, C., Battaglia, C., \& Fickenscher, A. Birth outcomes in Colorado's undocumented immigrant population. BMC Public Health, 2005;5(1):100. https://doi.org/10.1186/1471-2458-5-100

15. Guendelman, S., \& Jasis, M. Giving birth across the border: The San Diego-Tijuana connection. Social Science \& Medicine, 1992;34(4):419-425. https://doi.org/10.1016/0277-9536(92)90302-7

16. Kelaher, M., \& Jessop, D. J. Differences in low-birthweight among documented and undocumented foreign-born and US-born Latinas. Social Science \& Medicine, 2002;55(12):2171-2175. https://doi.org/10.1016/S0277-9536(01)00360-4

17. Peak, C., \& Weeks, J. R. Does Community Context Influence Reproductive Outcomes of Mexican Origin Women in San Diego, California? Journal of Immigrant Health, 2002;4(3):125-136. https://doi.org/10.1023/A:1015646800549

18. Migration Policy Institute. Unauthorized Immigrant Population Profiles. MPI. 2016. https://www.migrationpolicy.org/programs/us-immigration-policy-program-datahub/unauthorized-immigrant-population-profiles

19. Children's Hospital of Philadelphia. Low Birthweight. Chop.edu. 2020. https://www.chop.edu/conditions-diseases/lowbirthweight\#: : text=The $\% 20$ weight $\% 20$ is $\% 20$ compared $\% 20$ with,are $\% 20$ considered $\% 20$ very\%20low\%20birthweight

20. Radford, J. \& Noe-Bustamante, L. Facts on U.S. Immigrants, 2017. Pew Research Center: Hispanic Trends. 2019. https://www.pewresearch.org/hispanic/2019/06/03/factson-u-s-immigrants/ 


\section{Data sets}

1. James Bachmeier, Jennifer Van Hook. Unauthorized status in the U.S. 2016. https://www.migrationpolicy.org/programs/us-immigration-policy-program-datahub/unauthorized-immigrant-population-profiles

2. MIT Election Data and Science Lab. County Presidential Election Returns. 2016. https://doi.org/10.7910/DVN/VOQCHQ

3. United States Census Bureau. County Population by Characteristics. 2016. https://www.census.gov/data/tables/time-series/demo/popest/2010s-counties-detail.html

4. United States Census Bureau. Small Area Income and Poverty Estimates. 2016. https://www.census.gov/datatools/demo/saipe/\#/?map geoSelector $=$ aa $\_\& m a p$ yearSelector $=2016 \&$ s year $=2018,201$ $\underline{6}$

5. United States Census Bureau. Educational Attainment. 2016. https://data.census.gov/cedsci/table? $\mathrm{q}=$ education $\& \mathrm{~g}=0100000 \mathrm{US} .050000 \&$ hidePreview $=\mathrm{t}$ rue \& tid $=$ ACSST1Y2016.S1501\& $\mathrm{t}=$ Education

6. CDC Wonder. Natality data sets. 2016. https://wonder.cdc.gov/natality-expandedcurrent.html

7. CDC Wonder. Birth/Infant Death Records data sets. 2016. https://wonder.cdc.gov/controller/datarequest/D69 


\section{APPENDIX}

Figure 1
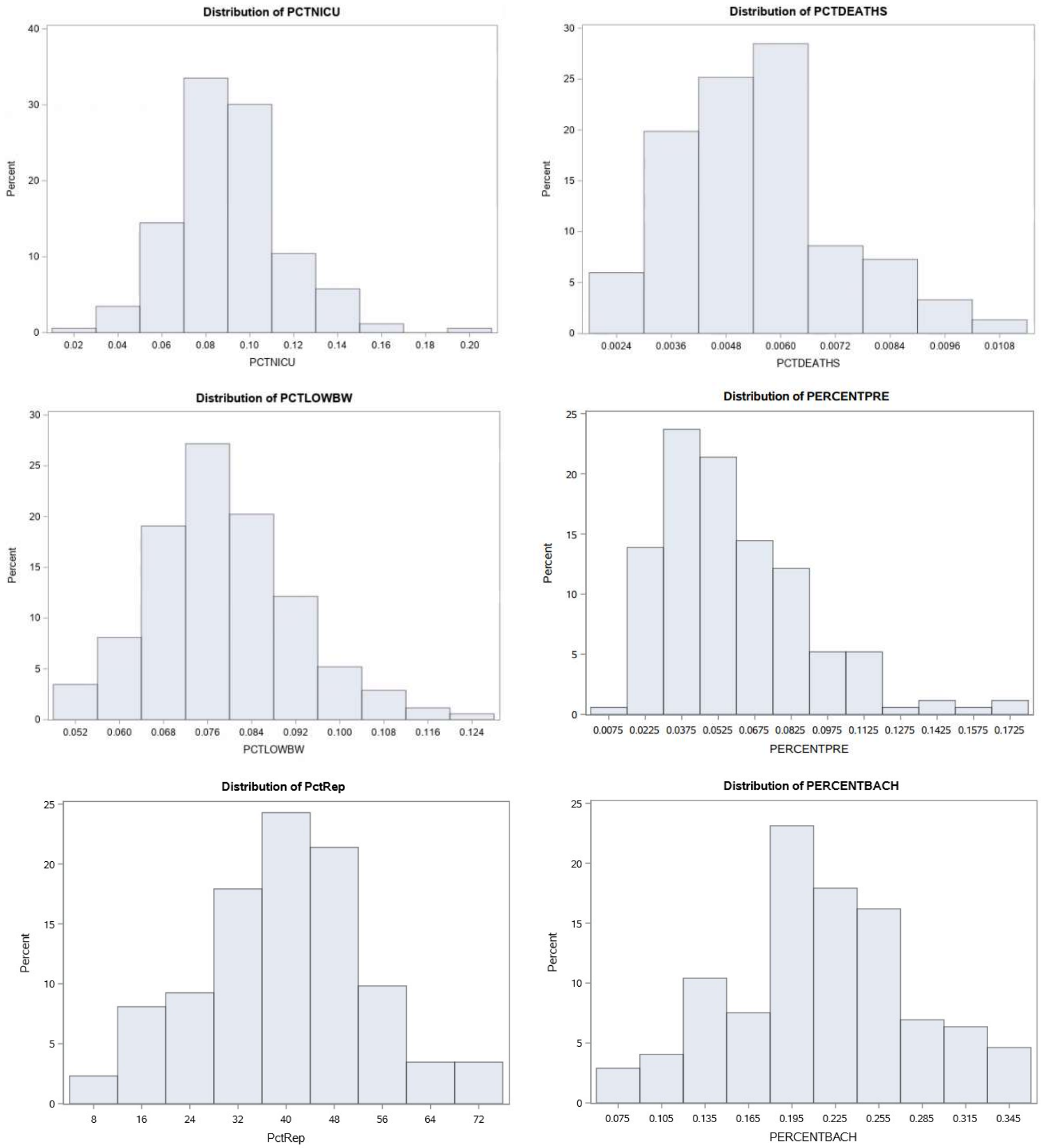

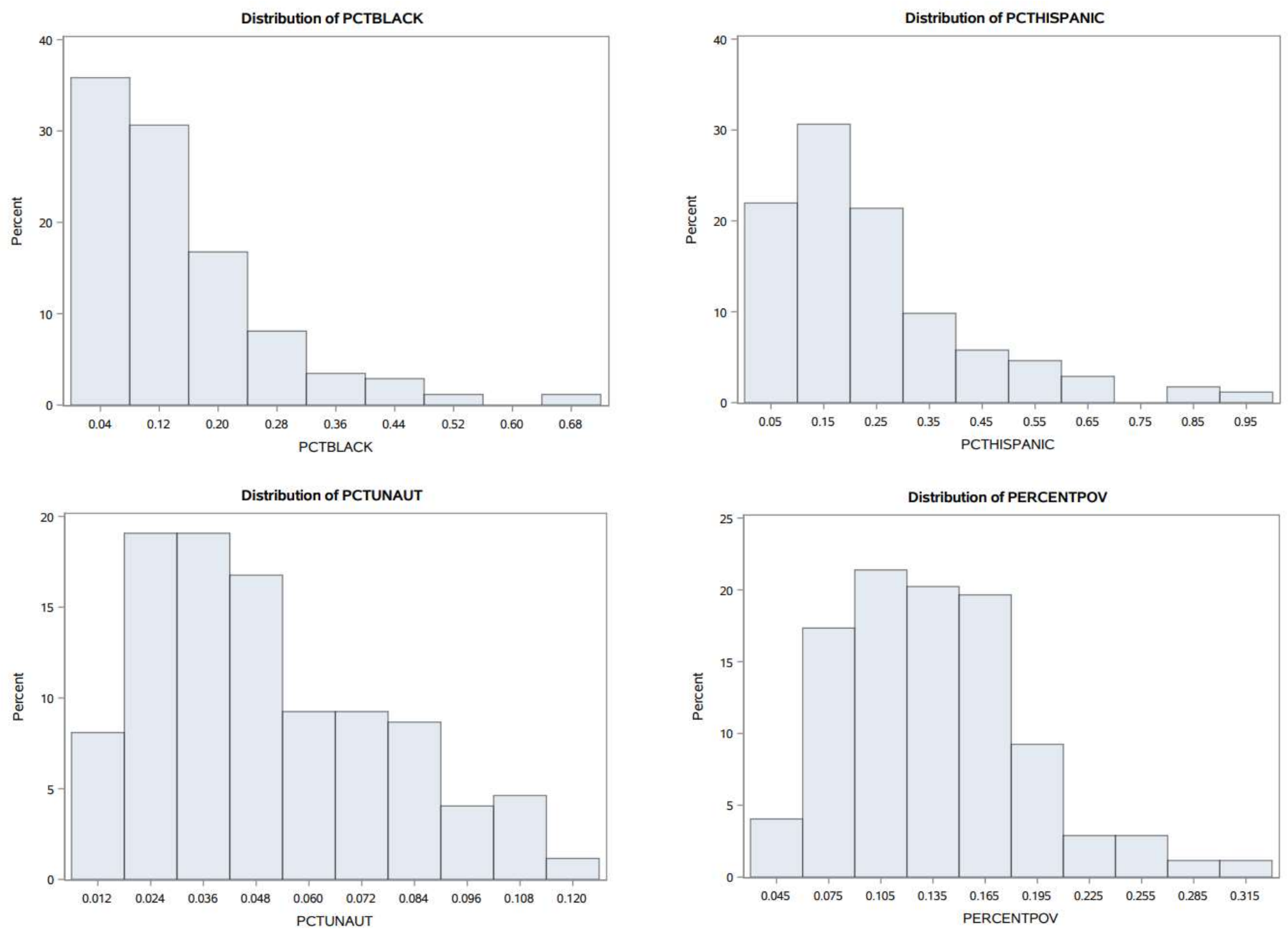

Table 3

NICU

\begin{tabular}{|l|c|}
\hline Explanatory Variable & Correlation \\
\hline Frequency Undocumented & 0.85 \\
\hline Frequency Below Poverty & 0.94 \\
\hline Frequency Voted Republican & 0.78 \\
\hline Frequency w/ Bachelor's Degree & 0.88 \\
\hline Frequency Hispanic/Latino & 0.83 \\
\hline Frequency African American & 0.81 \\
\hline Frequency Births w/ Late/No Prenatal Care & 0.82 \\
\hline
\end{tabular}


Low Birthweight

\begin{tabular}{|l|c|}
\hline Explanatory Variable & \\
\hline Frequency Undocumented & Correlation \\
\hline Frequency Below Poverty & 0.87 \\
\hline Frequency Voted Republican & 0.96 \\
\hline Frequency w/ Bachelor's Degree & 0.81 \\
\hline Frequency Hispanic/Latino & 0.90 \\
\hline Frequency African American & 0.87 \\
\hline Frequency Births w/ Late/No Prenatal Care & 0.86 \\
\hline
\end{tabular}

Infant Mortality

\begin{tabular}{|l|c|}
\hline Explanatory Variable & Correlation \\
\hline Frequency Undocumented & 0.78 \\
\hline Frequency Below Poverty & 0.92 \\
\hline Frequency Voted Republican & 0.78 \\
\hline Frequency w/ Bachelor's Degree & 0.82 \\
\hline Frequency Hispanic/Latino & 0.80 \\
\hline Frequency African American & 0.81 \\
\hline Frequency Births w/ Late/No Prenatal Care & 0.86 \\
\hline
\end{tabular}

\section{Table 4}

Negative Binomial Regression results

\begin{tabular}{|l|l|l|l|l|l|l|l|}
\hline & DF & Estimate & $\begin{array}{l}\text { Standard } \\
\text { Error }\end{array}$ & \multicolumn{2}{l|l}{$\begin{array}{l}\text { Confidence } \\
\text { Interval }\end{array}$} & $\begin{array}{l}\text { Chi- } \\
\text { squared }\end{array}$ & $\begin{array}{l}\text { P- } \\
\text { value }\end{array}$ \\
\hline Intercept & 1 & 6.35 & 0.76 & 4.86 & 7.85 & 69.20 & $<0.01$ \\
\hline Percent Undocumented & 1 & 0.08 & 3.53 & -6.84 & 7.00 & 0.00 & 0.98 \\
\hline Percent in Poverty & 1 & 1.90 & 2.16 & -2.34 & 6.13 & 0.77 & 0.38 \\
\hline Percent African Am. & 1 & 1.68 & 0.85 & 0.01 & 3.35 & 3.87 & 0.05 \\
\hline
\end{tabular}




\begin{tabular}{|l|l|l|l|l|l|l|l|}
\hline Percent Hispanic & 1 & 0.93 & 0.77 & -0.58 & 2.44 & 1.46 & 0.23 \\
\hline Percent Republican & 1 & -1.22 & 0.65 & -2.49 & 0.05 & 3.54 & 0.06 \\
\hline Percent w/ Bach Degree & 1 & 1.83 & 1.77 & -1.64 & 5.29 & 1.07 & 0.30 \\
\hline $\begin{array}{l}\text { Percent with Late/No } \\
\text { Prenatal Care }\end{array}$ & 1 & -1.26 & 2.41 & -5.98 & 3.46 & 0.28 & 0.60 \\
\hline Dispersion & 1 & 0.60 & 0.06 & 0.49 & 0.73 & & \\
\hline
\end{tabular}

Analysis of Maximum Likelihood of Parameter Estimates. The Negative Binomial model with Admission to NICU as the response variable.

\begin{tabular}{|l|l|l|l|l|l|l|l|}
\hline & DF & Estimate & $\begin{array}{l}\text { Standard } \\
\text { Error }\end{array}$ & \multicolumn{2}{|l|}{$\begin{array}{l}\text { Confidence } \\
\text { Interval }\end{array}$} & $\begin{array}{l}\text { Chi- } \\
\text { squared }\end{array}$ & $\begin{array}{l}\text { P- } \\
\text { value }\end{array}$ \\
\hline Intercept & 1 & 5.96 & 0.72 & 4.54 & 7.38 & 67.84 & $<0.01$ \\
\hline Percent Undocumented & 1 & -1.82 & 3.50 & -8.68 & 5.04 & 0.27 & 0.60 \\
\hline Percent in Poverty & 1 & 1.69 & 2.11 & -2.46 & 5.83 & 0.64 & 0.42 \\
\hline Percent African Am. & 1 & 1.94 & 0.81 & 0.36 & 3.52 & 5.81 & 0.02 \\
\hline Percent Hispanic & 1 & 1.48 & 0.76 & -0.01 & 2.98 & 3.79 & 0.05 \\
\hline Percent Republican & 1 & -1.46 & 0.61 & -2.67 & -0.26 & 5.66 & 0.02 \\
\hline Percent w/ Bach Degree & 1 & 2.83 & 1.69 & -0.49 & 6.15 & 2.79 & 0.09 \\
\hline $\begin{array}{l}\text { Percent with Late/No } \\
\text { Prenatal Care }\end{array}$ & 1 & 0.18 & 2.31 & -4.36 & 4.71 & 0.01 & 0.94 \\
\hline Dispersion & 1 & 0.56 & 0.06 & 0.45 & 0.69 & & \\
\hline
\end{tabular}

Analysis of Maximum Likelihood of Parameter Estimates. The Negative Binomial model with Low Birthweight as the response variable.

\begin{tabular}{|l|l|l|l|l|l|l|l|}
\hline & DF & Estimate & $\begin{array}{l}\text { Standard } \\
\text { Error }\end{array}$ & \multicolumn{2}{|l|}{$\begin{array}{l}\text { Confidence } \\
\text { Interval }\end{array}$} & $\begin{array}{l}\text { Chi- } \\
\text { squared }\end{array}$ & $\begin{array}{l}\text { P- } \\
\text { value }\end{array}$ \\
\hline Intercept & 1 & 2.91 & 0.72 & 1.48 & 4.33 & 16.06 & $<0.01$ \\
\hline Percent Undocumented & 1 & 1.38 & 3.76 & -5.99 & 8.75 & 0.14 & 0.71 \\
\hline Percent in Poverty & 1 & 5.49 & 2.08 & 1.42 & 9.55 & 6.99 & 0.01 \\
\hline
\end{tabular}




\begin{tabular}{|l|l|l|l|l|l|l|l|}
\hline Percent African Am. & 1 & 0.83 & 0.78 & -0.70 & 2.35 & 1.13 & 0.29 \\
\hline Percent Hispanic & 1 & 0.43 & 0.78 & -1.09 & 1.96 & 0.31 & 0.58 \\
\hline Percent Republican & 1 & -0.60 & 0.65 & -1.88 & 0.68 & 0.84 & 0.36 \\
\hline Percent w/ Bach Degree & 1 & 1.60 & 1.71 & -1.76 & 4.95 & 0.87 & 0.35 \\
\hline $\begin{array}{l}\text { Percent with Late/No } \\
\text { Prenatal Care }\end{array}$ & 1 & 2.71 & 2.51 & -2.21 & 7.63 & 1.17 & 0.28 \\
\hline Dispersion & 1 & 0.48 & 0.05 & 0.39 & 0.60 & & \\
\hline
\end{tabular}

Analysis of Maximum Likelihood of Parameter Estimates. The Negative Binomial model with Infant Mortality as the response variable.

Figure 2

Correlation Scatterplots: Percent Undocumented with all other explanatory variables
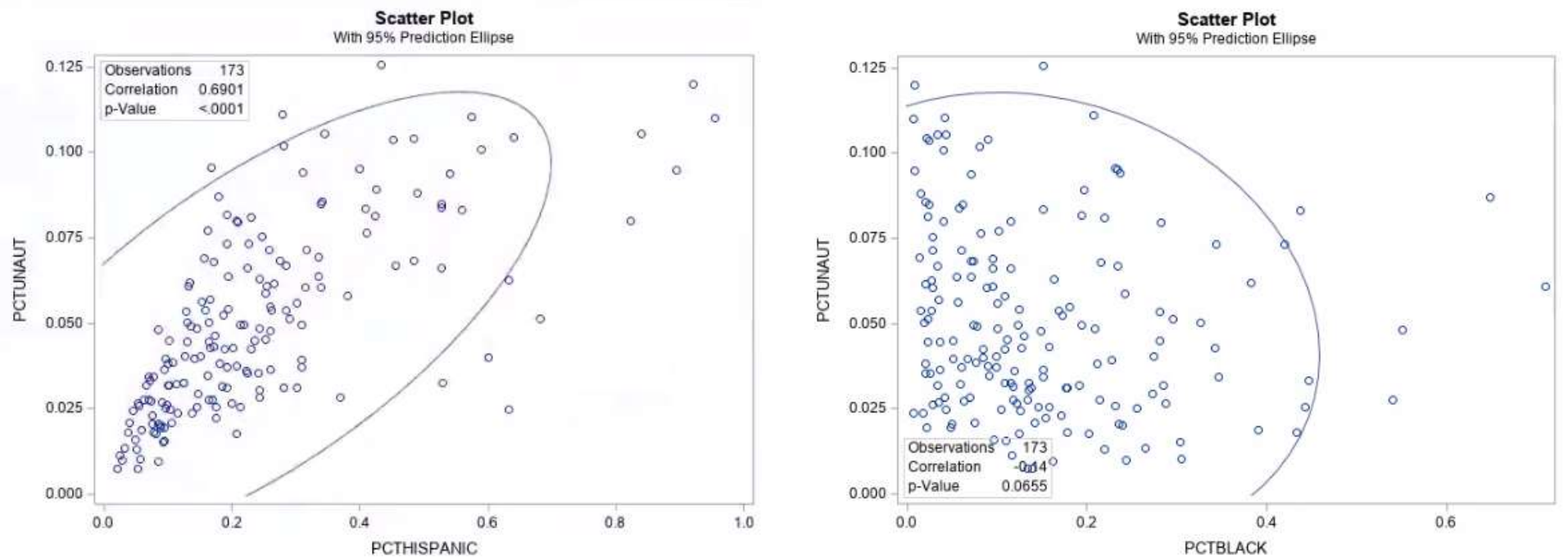

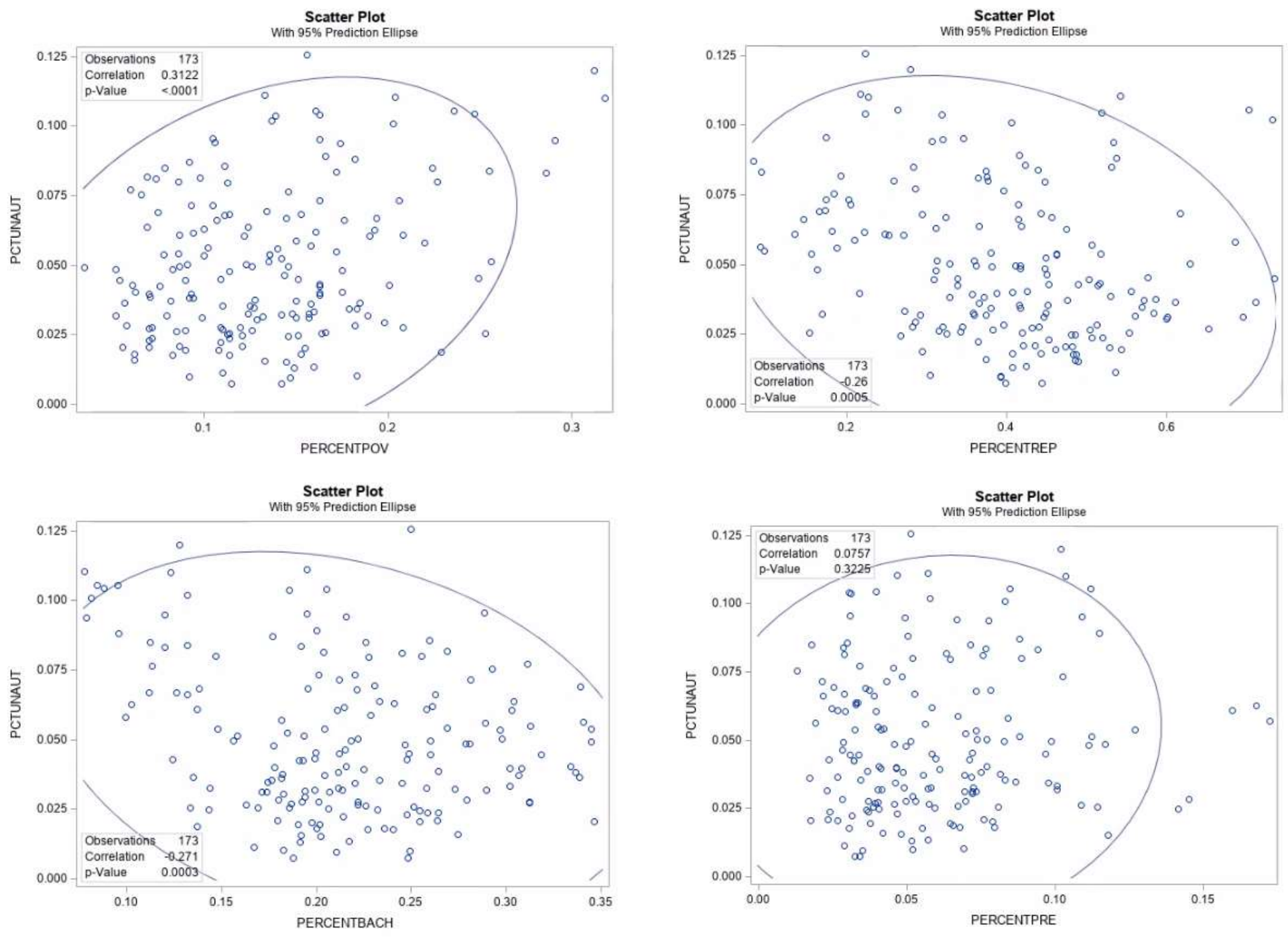


\section{Declarations}

Ethics approval and consent to participate

The Public Health Service Act (42 U.S.C. $242 \mathrm{~m}(\mathrm{~d})$ ) provides that the data collected by the National Center for Health Statistics (NCHS) may be used only for the purpose for which they were obtained; any effort to determine the identity of any reported cases, or to use the information for any purpose other than for health statistical reporting and analysis, is against the law. Therefore users will:

- Use these data for health statistical reporting and analysis only.

- For sub-national geography, do not present or publish birth counts of 9 or fewer or birth rates based on counts of nine or fewer (in figures, graphs, maps, tables, etc.).

- Make no attempt to learn the identity of any person or establishment included in these data.

- Make no disclosure or other use of the identity of any person or establishment discovered inadvertently and advise the NCHS Confidentiality Officer of any such discovery.

\section{Consent for publication}

Not applicable.

\section{Availability of data and materials}

All data generated or analyzed during this study are included in this published article and its supplementary information files.

\section{Competing interests}

The authors declare that they have no competing interests.

\section{Funding}

All funding is attributable to Brigham Young University.

\section{Authors' contributions}

BB collected most of the data and performed statistical analyses. BB interpreted results and was a major contributor in writing the manuscript. JS also aided in conducting the negative binomial regression analyses. IT conducted a literature review of the current literature and wrote the introduction of the manuscript. RR collected political data for analysis. CS guided and mentored the entirety of the research. All authors read and approved the final manuscript.

\section{Acknowledgements}

Acknowledgements go to Shelby Geurts, Catherine Bakare, and Brian Allen, for contributing to the initial conception of the research project.

\section{Authors' information}


All authors besides Chantel Sloan were undergraduate Public Health students at Brigham Young University at the time of completion of the manuscript. Chantel Sloan is a professor at Brigham Young University and provided her expertise to help carry out the research. 
Figures
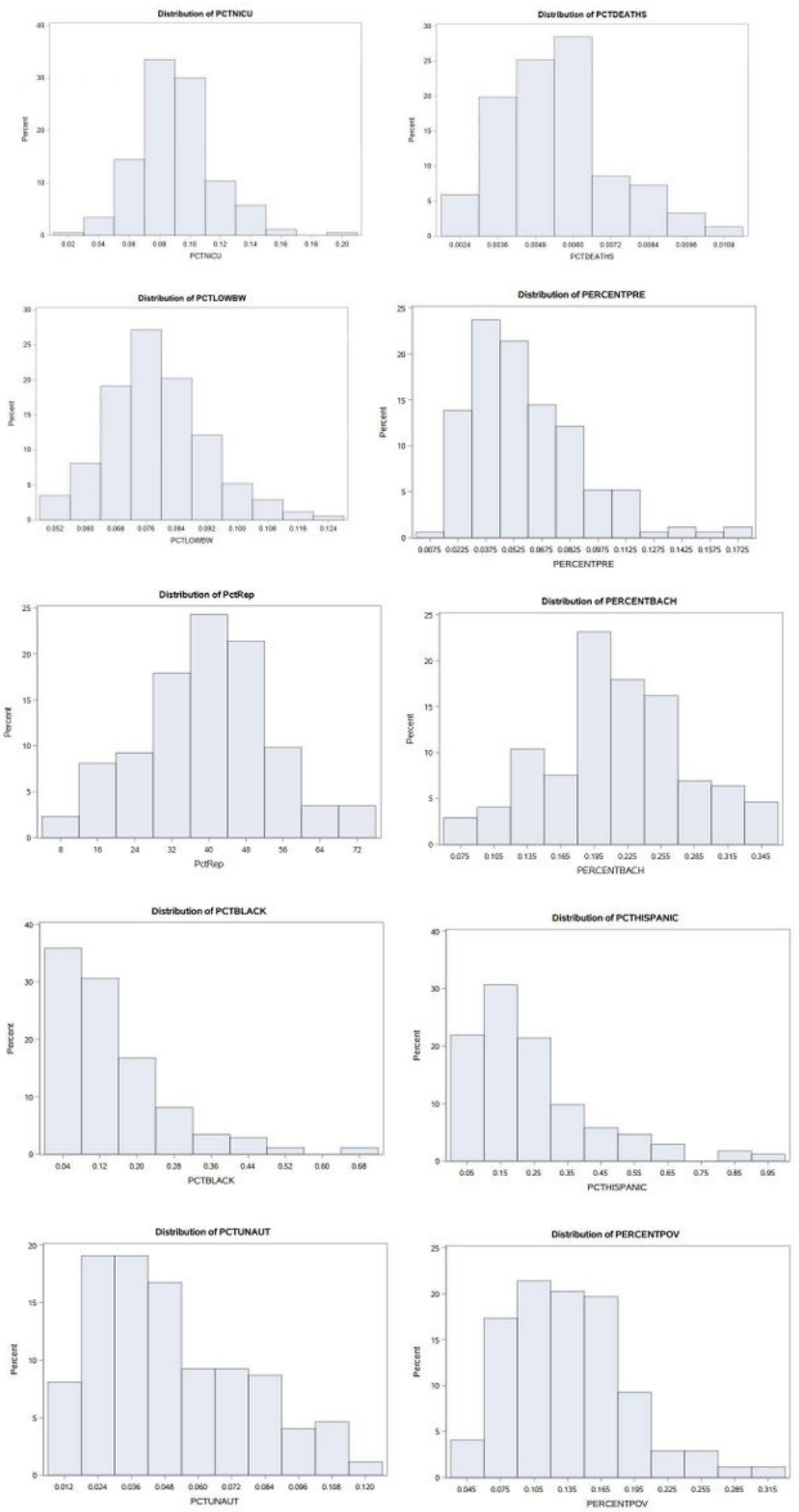

\section{Figure 1}

The analysis included birth outcome, immigration status, socioeconomics and political leanings from 173 counties in the United States. 

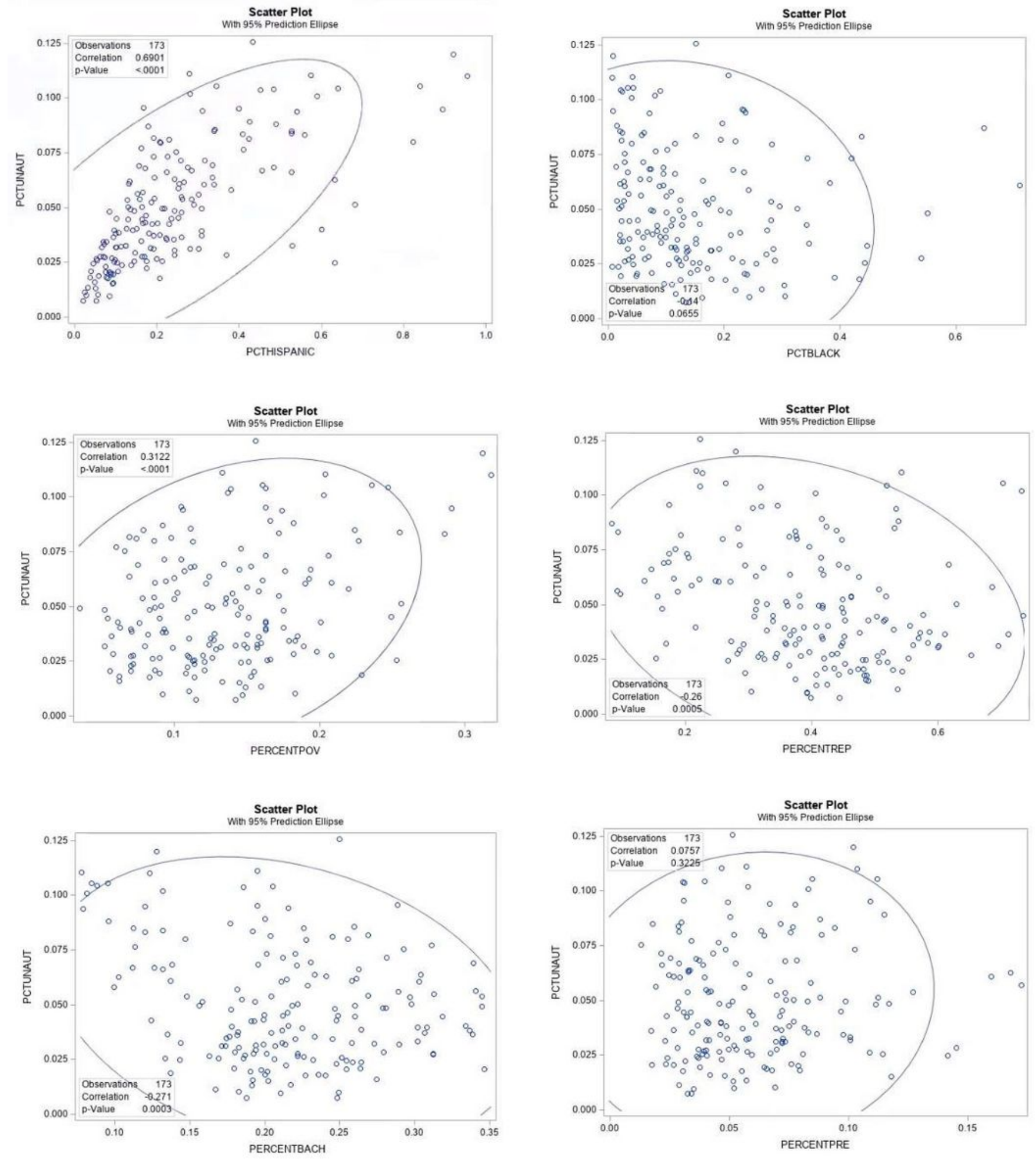

\section{Figure 2}

Correlation Scatterplots: Percent Undocumented with all other explanatory variables 

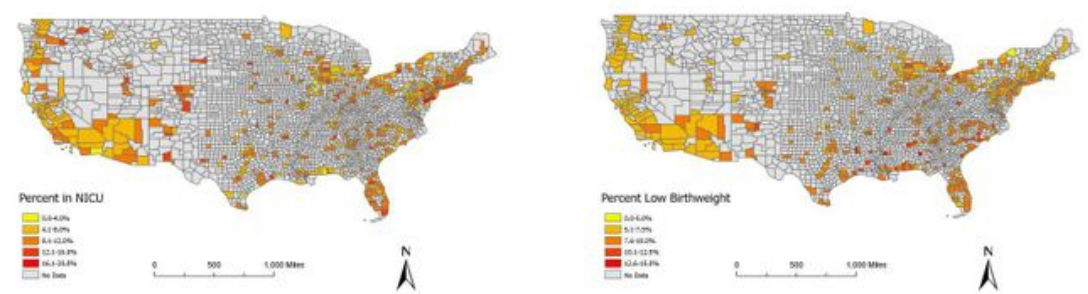

U.S. Infant Mortality

Unauthorized Immigrants in the U.S.
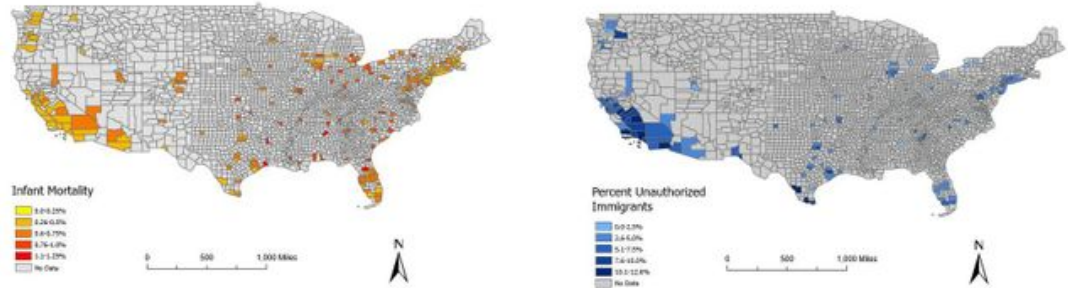

Percent of Births with Late or No Prenatal Care

Percent of Population in Poverty

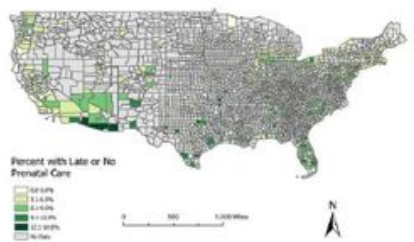

Hispanic/Latino Population in the U.S.

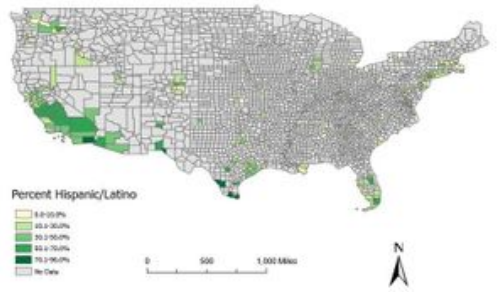

African American Population in the U.S.

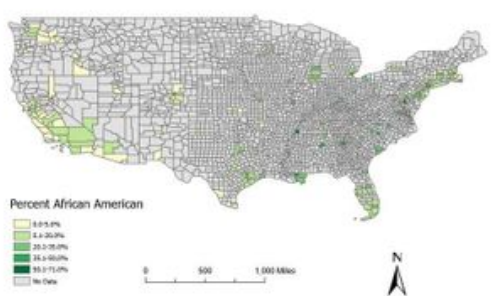

Percent Voted Republican 2016

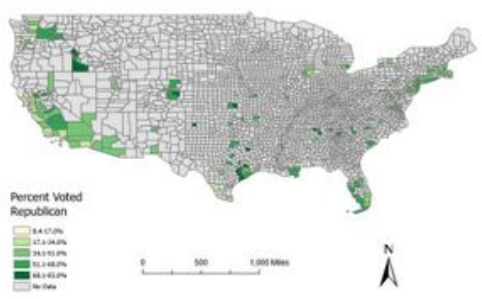

Percent of U.S. Population with Bachelor's Degree

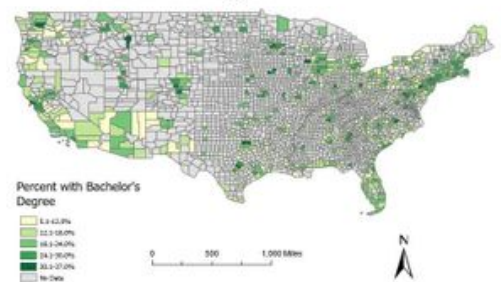

\section{Figure 3}

Maps. Note: The designations employed and the presentation of the material on this map do not imply the expression of any opinion whatsoever on the part of Research Square concerning the legal status of any country, territory, city or area or of its authorities, or concerning the delimitation of its frontiers or boundaries. This map has been provided by the authors. 